\title{
Application of a Novel Metal Artifact Correction Algorithm in Flat-Panel CT After Coil Embolization of Brain Aneurysms: Intraindividual Comparison
}

\section{Intraindividueller Vergleich der Anwendung eines neuen Algorithmus zur Metallartefaktkorrektur bei Flächendetektor-CT nach Coil-Embolisation von Hirnarterienaneurysmen}

Authors

Affiliations
J.-H. Buhk ${ }^{1}$, M. Groth ${ }^{1}$, S. Sehner ${ }^{2}$, J. Fiehler ${ }^{1}$, N. O. Schmidt ${ }^{3}$, U. Grzyska ${ }^{1}$

Dept. of Diagnostic and Interventional Neuroradiology, University Medical Center Hamburg Eppendorf, Hamburg

Dept. of Medical Biometry and Epidemiology, University Medical Center Hamburg Eppendorf, Hamburg

Dept. of Neurosurgery, University Medical Center Hamburg Eppendorf, Hamburg

Key words
brain
CT
interventional procedures
aneurysm
technical aspects

eingereicht 26.4 .2013

akzeptiert 14.6.2013

Bibliography

Dol http://dx.doi.org/ 10.1055/s-0033-1350117

Published online: 15.7.2013

Fortschr Röntgenstr 2013; 185 :

824-829 ๑ Georg Thieme

Verlag KG Stuttgart · New York . ISSN 1438-9029

\footnotetext{
Correspondence

Dr. Jan-Hendrik Buhk

Klinik und Poliklinik für und Intervention,

Eppendorf

Martinistr. 52

20246 Hamburg

Germany

Tel.: $01522 / 2815188$

Fax: 040/7 41054640

jbuhk@uke.de
}

Neuroradiologische Diagnostik

Universitätsklinikum Hamburg-

\section{Zusammenfassung}

$\nabla$

Zielsetzung: Evaluation eines neuen Rekonstruktionsalgorithmus zur Korrektur von Aufhärtungsartefakten durch metallene Implantate bei der Computertomografie an einer C-Bogen-Angiografie-Anlage mit Flächendetektoren (FD-CT).

Material und Methoden: 16 Datensätze zerebraler FD-CT Akquisitionen nach Coil-Embolisation von Hirnarterienaneurysmen im Rahmen einer akuten Subarachnoidalblutung wurden verwendet. Die Daten wurden mit einem Weichteil-Kernel zu isotropen Quellschichten rekonstruiert, jeweils mit und ohne Anwendung des neuen Rekonstruktionsfilters zur Metallartefaktreduktion. Bildbetrachtung und Auswertung erfolgten an einer radiologischen Arbeitsstation unter Verwendung multiplanarer Reformatierungen. Als anatomischer Goldstandard diente das präinterventionelle native Mehrzeilen-Computertomogramm (MS-CT). Zwei unabhängige Radiologen führten die Bildbewertung anhand einer definierten 4Punkte-Skala durch. Die statistische Prüfung erfolgte in einem Random-Intercept-Modell.

Ergebnisse: Die Interrater-Reliabilität war sehr hoch (ICC: $86 \%$ ). Die Bewertungen für die betroffene Region waren signifikant besser unter Anwendung der Metallartefaktreduktion. Die subjektive Qualität der Darstellung der übrigen Regionen in der FD-CT wurde durch den zusätzlichen Filter nicht beeinflusst.

Schlussfolgerungen: Der neue Metallartefaktreduktionsalgorithmus ermöglicht eine verbesserte Erkennbarkeit der direkten Umgebung eines akut behandelten Aneurysmas in der FD-CT bei konstanter Gesamtqualität der Untersuchung.

\section{Abstract \\ $\nabla$}

Purpose: To evaluate a novel algorithm for correcting beam hardening artifacts caused by metal implants in computed tomography performed on a C-arm angiography system equipped with a flat panel (FP-CT).

Materials and Methods: 16 datasets of cerebral FP-CT acquisitions after coil embolization of brain aneurysms in the context of acute subarachnoid hemorrhage have been reconstructed by applying a soft tissue kernel with and without a novel reconstruction filter for metal artifact correction. Image reading was performed in multiplanar reformations (MPR) in average mode on a dedicated radiological workplace in comparison to the preinterventional native multisection CT (MS-CT) scan serving as the anatomic gold standard. Two independent radiologists performed image scoring following a defined scale in direct comparison of the image data with and without artifact correction. For statistical analysis, a random intercept model was calculated.

Results: The inter-rater agreement was very high (ICC $=86.3 \%$ ). The soft tissue image quality and visualization of the CSF spaces at the level of the implants was substantially improved. The additional metal artifact correction algorithm did not induce impairment of the subjective image quality in any other brain regions.

Conclusion: Adding metal artifact correction to FP-CT in an acute postinterventional setting helps to visualize the close vicinity of the aneurysm at a generally consistent image quality.

Citation Format:

- Buhk JH, Groth M, Sehner S et al. Application of a Novel Metal Artifact Correction Algorithm in Flat-Panel CT After Coil Embolization of Brain Aneurysms: Intraindividual Comparison. Fortschr Röntgenstr 2013; 185: 824-829 


\section{Introduction}

\section{$\nabla$}

Flat-panel computed tomography (FP-CT) is a still relatively novel technique for generating CT-like images derived from a rotational acquisition by $\mathrm{C}$-arm-mounted flat detectors, usually mounted on an angiography system [1-8]. Several applications of this technique have been described taking advantage of the - in comparison to conventional CT - very high spatial resolution, which allows precise delineation of intracranial implants like intracranial stents, especially remodeling stents, coils and clips [1, 923]. The soft tissue resolution of FP-CT is not as good as in conventional $\mathrm{CT}$, but has been reported as being sufficient for reliably depicting cerebrospinal fluid (CSF) spaces as well as intracerebral and subarachnoid hemorrhage $[2,4,7,12,24]$. The huge advantage of the method compared to conventional CT lies in the availability in the angiography lab, i.e. the acquisition is performed with the patient still on the table, and the intervention can be continued afterwards, if necessary.

However, there are still some drawbacks to FP-CT, which are similar to those of conventional CT: If larger amounts of highly radiopaque implants (e.g. large clips, coil package) are present, substantial beam hardening artifacts on the level of these implants occur. When an adjacent stent (high contrast object) is to be displayed, changing the Hounsfield settings to a wider window may help in such a situation. However if the subarachnoid spaces or the local brain parenchyma are in question and narrow Hounsfield windowing is necessary, none of the so far commercially available reconstruction algorithms have been able to minimize these artifacts.

In this study we present first clinical results from applying a new reconstruction filter, which already is a product and can be added to the normal FP-CT soft tissue reconstruction kernel in order to minimize particular beam hardening artifacts generated by highly radiopaque (metal) materials.

We performed an intraindividual comparison in a collective of patients who had undergone coil embolization of a brain aneurysm, which had acutely bled. FP-CT scans were performed directly after the embolization procedure in order to exclude new hemorrhage and progressive hydrocephalus. For evaluation the same FP-CT raw data have been reconstructed with and without the new metal artifact reconstruction (MAR) filter algorithm. Preinterventional conventional multisection CT (MS-CT) served as the standard of reference.

\section{Methods}

$\nabla$

The local institutional review board approved this study (WF 59/ 12). The requirement for written informed consent was waived.

\section{Data acquisition and reconstruction}

Raw data from FP-CT acquisitions of 16 patients ( 5 male, 11 female; mean age 55 years; age range: 28 - 76 years) were collected and used for this study. All exams were performed directly following coil embolization of a ruptured cerebral aneurysm on an Allura Xper FD 20/20 ${ }^{\mathrm{TM}}$ angiography system (Philips Healthcare, Best, The Netherlands).

The acquisition parameters were as follows: 20 s rotational ("propeller") acquisition over $220^{\circ}, 617$ single frames (frame rate: $30 / \mathrm{s}$ ), $48 \mathrm{~cm}$ detector field of view (1024 acquisition matrix), slightly collimated in the craniocaudal direction.

All exams had initially been reconstructed by applying default parameters, i.e. soft tissue kernel with conventional filtering (beam hardening, correction for scattered radiation) and an isotropic voxel size of $0.9 \times 0.9 \times 0.9 \mathrm{~mm}^{3}$.

For study evaluation a second and third reconstruction were performed in a slightly smaller reconstruction volume with a somewhat higher spatial resolution (isotropic voxel size $0.6 \times 0.6 \times 0.6 \mathrm{~mm}^{3}$ ). For reference, the standard soft tissue kernel was used in a $2^{\text {nd }}$ reconstruction. In the $3^{\text {rd }}$ reconstruction, the new metal artifact reduction (MAR) filter was added to the soft tissue kernel; all other parameters were the same. The basic principle of the MAR algorithm lies in reconstructing an additional "artifact volume", which is not visually displayed but automatically subtracted from the entire volume to achieve the final MAR volume. Since an extra full reconstruction is required, reconstruction time is doubled when applying MAR.

All resulting image data (reference images as well as MAR images) were documented in multiplanar reformations (MPR) in transverse, coronal and sagittal orientations in average mode ( $4 \mathrm{~mm}$ slice thickness, continuously) and archived in the center's picture archiving and communication system (PACS, IW, GE Healthcare, Milwaukee, MI). Image reading and scoring were performed on a dedicated PACS workstation with approval for diagnostic reading.

Preinterventional conventional MS-CT scans were performed in helical mode on a Brilliance iCT 256 ${ }^{\mathrm{TM}}$ scanner (Philips Healthcare, Best, The Netherlands) using standard resolution. Reconstruction featured filtered back projection and standard filter kernel (UB). Standard PACS documentation of MS-CT soft tissue images was performed in MPR in transverse, coronal and sagittal orientations in average mode ( $4 \mathrm{~mm}$ slice thickness, continuously).

\section{Subjective image evaluation}

Two experienced radiologists (J.B. and M. G., each $>6$ years experience, thereof $>2$ years in neuroradiology) performed scoring of the image data by applying a precisely defined 4-point scale with regard to the delineation of the internal and external CSF spaces and the depictability of hemorrhage. Discrimination of gray and white matter was also scored serving as a surrogate parameter for CT image quality. Scorings were performed in analogy to former work on the same topic $[12,25]$. The particular criteria for image evaluation as used in the current study are summarized in Table 1. For scoring, the preinterventional MSCT, non-MAR FP-CT and MAR FP-CT were displayed independ-

Table 1 Definition of subjective image evaluation criteria (see also - Fig. 1). Anatomy and pathology were scored with regard to the following regions: internal CSF spaces (supra- and infratentorial), external CSF spaces (supra- and infratentorial), delineation of the hemorrhage (remote from and on the level of the aneurysm). Artifacts were scored with respect to the level of the aneurysm and the exam as a whole.

Tab. 1 Definition der subjektiven Kriterien der Bildbewertung (siehe auch - Abb. 1): Zur Bewertung der Anatomie und Pathologie wurden folgende Regionen abgefragt: innere und äußere Liquorräume (jeweils supra- und infratentoriell), Darstellung der Blutung (auf Niveau des Aneurysmas vs. übrige Regionen). Artefakte wurden sowohl speziell für das Niveau des Aneurysmas als auch für die gesamte Untersuchung bewertet.

\begin{tabular}{|lll|}
\hline score & criteria anatomy/pathology & criteria artifacts \\
\hline 0 & not diagnostic & serious artifacts, intolerable \\
\hline 1 & $\begin{array}{l}\text { suboptimal quality, hardly } \\
\text { diagnostic }\end{array}$ & $\begin{array}{l}\text { serious artifacts, hardly } \\
\text { tolerable }\end{array}$ \\
\hline 2 & sufficient diagnostic quality & moderate artifacts, tolerable \\
\hline 3 & good diagnostic quality & marginal or no artifacts \\
\hline
\end{tabular}


ently from each other and under reporting conditions. The readers were allowed to change Hounsfield windowing and to scroll through the complete datasets.

In detail, the readers were asked to evaluate the quality of the depiction of the following anatomical landmarks (for criteria see - Table 1): internal and external craniospinal fluid (CSF) spaces, divided into supra- and infratentorial compartments; gray-white differentiation in the central region; hemorrhage overall and hemorrhage at aneurysm level.

Table 2 The table gives an overview of basic clinical data as well as aneurysm size and location.

Tab. 2 Die Tabelle gibt einen Überblick über klinische Basisdaten aller untersuchten Patienten und Aneurysmen.

\begin{tabular}{|c|c|c|c|c|}
\hline pat. \# & sex & age & aneurysm location & $\begin{array}{l}\text { mean aneurysm } \\
\text { diameter (mm) }\end{array}$ \\
\hline 1 & $f$ & 46 & right P-COM & 5 \\
\hline 2 & $\mathrm{f}$ & 47 & left P-COM & 12 \\
\hline 3 & $f$ & 71 & $\mathrm{~A}-\mathrm{COM}$ & 3 \\
\hline 4 & $f$ & 53 & left P-COM & 8 \\
\hline 5 & $f$ & 75 & right $\mathrm{P}-\mathrm{COM}$ & 5 \\
\hline 6 & $f$ & 46 & $\mathrm{~A}-\mathrm{COM}$ & 7 \\
\hline 7 & $f$ & 36 & PICA & 5 \\
\hline 8 & $\mathrm{~m}$ & 51 & $\mathrm{~A}-\mathrm{COM}$ & 3 \\
\hline 9 & $\mathrm{~m}$ & 44 & right P-COM & 10 \\
\hline 10 & $f$ & 28 & left ICA & 22 \\
\hline 11 & $f$ & 58 & pericallosal artery & 2 \\
\hline 12 & $\mathrm{~m}$ & 56 & right P-COM & 12 \\
\hline 13 & $\mathrm{~m}$ & 50 & pericallosal artery & 6 \\
\hline 14 & $\mathrm{~m}$ & 76 & A-COM & 2 \\
\hline 15 & $f$ & 66 & left ICA & 22 \\
\hline 16 & $f$ & 73 & $\mathrm{~A}-\mathrm{COM}$ & 12 \\
\hline
\end{tabular}

ICA = internal carotid artery; $\mathrm{P}-\mathrm{COM}=$ posterior communicating artery; $\mathrm{A}-\mathrm{COM}=\mathrm{an}$ terior communicating artery; PICA = posterior inferior cerebellar artery
Additionally, the readers were asked to assess the artifact load of the exam in general and at the level of the aneurysm in particular (for criteria see $\bullet$ Table 1 ).

Since the size of the aneurysm has a direct relationship to the size of the final coil package - and therefore possibly to the artifact load to be expected -, it was included in the statistical evaluation. Also included was the location of the aneurysm. 0 Table 2 provides an overview of the basic clinical data.

\section{Statistical analysis}

Regarding data structure, clusters within the patients and clusters within the two raters, statistical analysis of the subjective scores was carried out by applying a mixed model with crossed random intercepts between both clusters. The anatomical landmarks and the imaging method were predictive variables. Additionally, the following confounders were included in the model: patients' sex, aneurysm location and size. Using the likelihood ratio test, we also checked whether size represented as volume (cubic), area (square) or diameter (linear) has the best predictive power. Interaction terms between aneurysm size, anatomical landmarks and imaging method as well as the interaction between imaging method and aneurysm location were evaluated. Marginal means with $95 \%$ confidence intervals (CI) were calculated for statistically significant variables. The inter-rater reliability was estimated.

Nominal p-values are reported without correction for multiplicity. P-values $<0.05$, two-sided were considered significant. All calculations were performed in STATA/SE 12.1.

\section{Results}

The inter-rater reliability is high (86.3\%, 95\%-CI [79.1\%, 90.4\%]). Looking at the goodness-of-fit measures and the likelihood ratio test, the model with the area approach for aneurysm size shows the best statistical fit (volume vs. area $p=0.5216$, no significant advantage for volume; area vs. diameter $\mathrm{p}<0.001$ significant advantage for area).

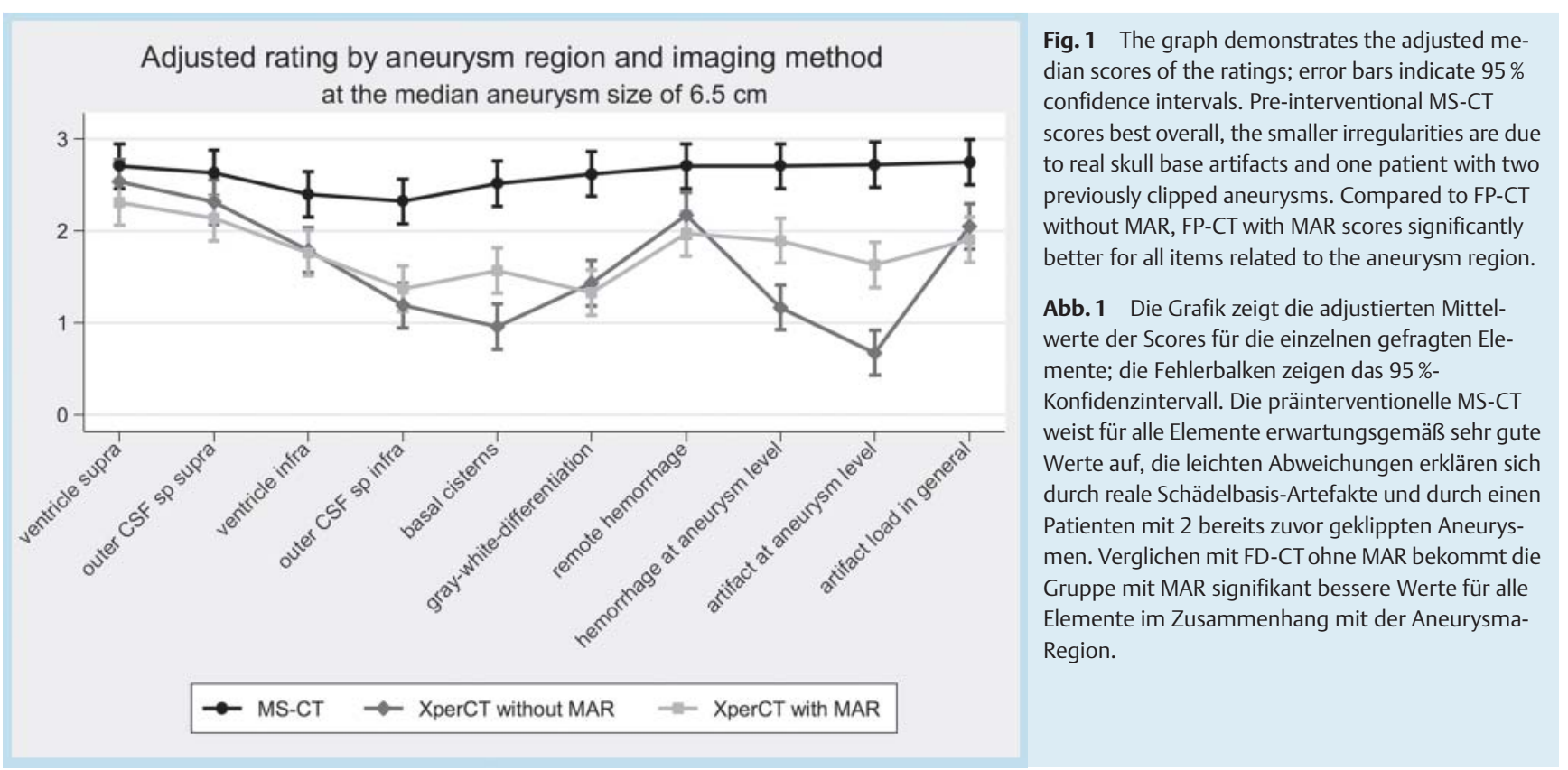



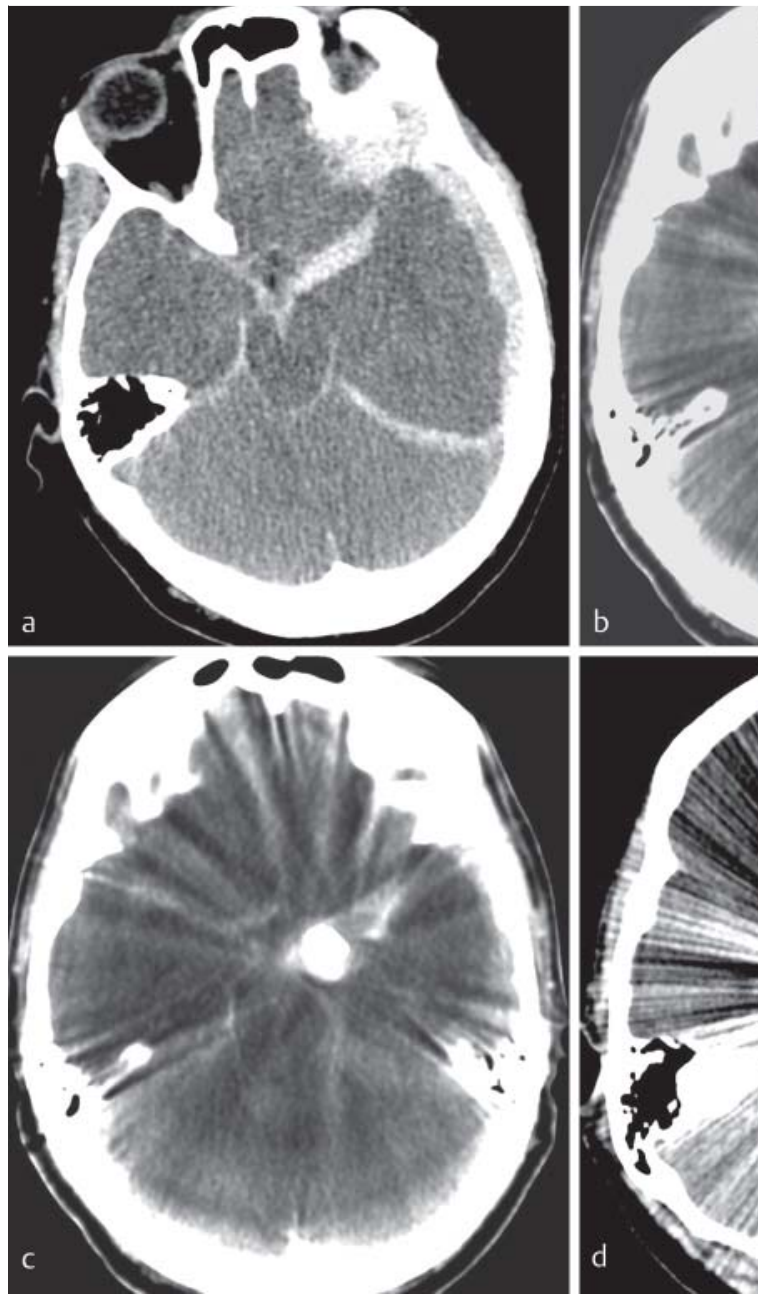

$\cdots$

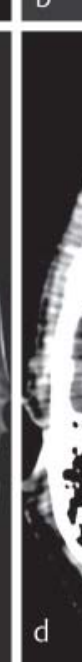

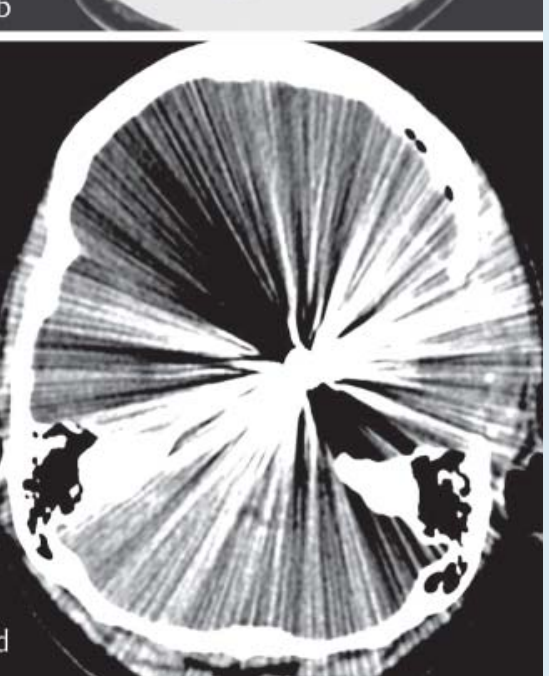

Fig. 2 Presented are images from a 53-year old female patient with subarachnoid hemorrhage

Hunt \& Hess grade V (pat. \#4). Conventional native brain MS-CT at admission reveals extensive subarachnoid hemorrhage in the basal cisterns as well as left temporal subdural hematoma (a). An $8 \mathrm{~mm}$ aneurysm at the origin of left posterior communicating artery was diagnosed and treated by coil embolization. Directly after the procedure, FP-CT was performed (b: without MAR, c: with MAR). The reconstruction with MAR applied (c) is still not free of artifact, however, the basal cisterns and the vicinity of the treated aneurysm are visualized much better. Even worse coil-related artifacts occur in the conventional MS-CT at follow-up after 48 hours (d).

Abb.2 Gezeigt ist die Bildgebung einer 53 Jahre alten Patientin mit Subarachnoidalblutung Hunt \& Hess Grad V (Pat. Nr. 4). Die konventionelle MS-CT bei Aufnahme zeigt eine ausgedehnte subarachnoidale und subdurale Blutung (a). Ein $8 \mathrm{~mm}$ messendes Aneurysma am Abgang der linken A. communicans posterior wurde diagnostiziert und mit Coil-Embolisation behandelt. Direkt nach der Prozedur wurde eine FD-CT angefertigt (b: ohne MAR, c: mit MAR). Die Rekonstruktion mit MAR (c) ist nicht frei von Artefakten, zeigt aber die basalen Zisternen im Bereich des Aneurysmas deutlich besser. Die MS-CT-Verlaufskontrolle nach 48 Stunden weist erhebliche Coil-bedingte Artefakte auf (d).

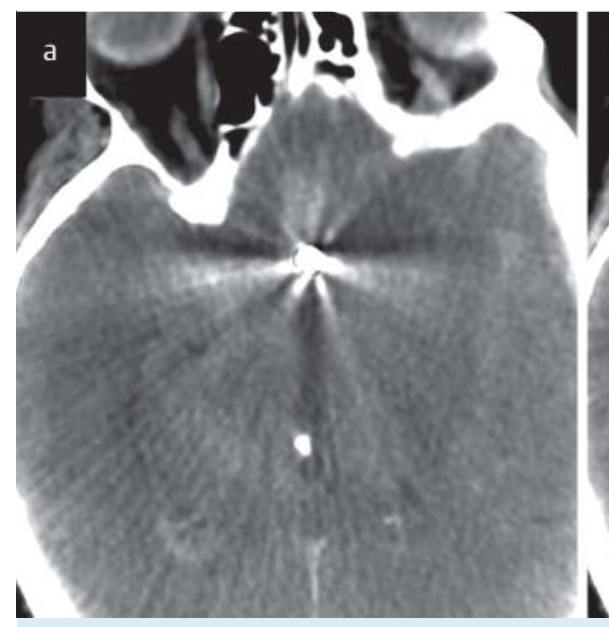

Fig. 3 Presented are postoperative FP-CT images from a 71-year-old female patient who suffered form subarachnoid hemorrhage Hunt \& Hess grade III from a small ( $3 \mathrm{~mm}$ ) aneurysm of the anterior communicating artery (pat. \#3; a: without MAR, b: with MAR). The images demonstrate the much more precise definition of the circumscribed hemorrhage in the close vicinity of the aneurysm when MAR is applied. However, the difference is not that marked due to the small coil volume.

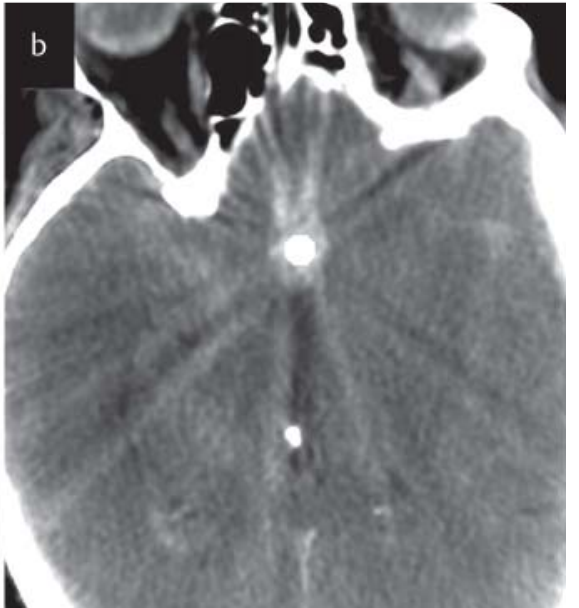

Abb. 3 Postoperative FD-CT einer 71 Jahre alten Patientin mit Subarachnoidalblutung Hunt \& Hess Grad III aus einem kleinen ( $3 \mathrm{~mm}$ ) Aneurysma der A. communicans anterior (Pat. Nr. 3; a: ohne MAR, b: mit MAR). Die direkte Umgebung des Aneurysmas ist mit Verwendung von MAR deutlich besser zu erkennen, allerdings sind die Unterschiede bei dem relativ geringen Coil-Volumen nicht allzu groß. 


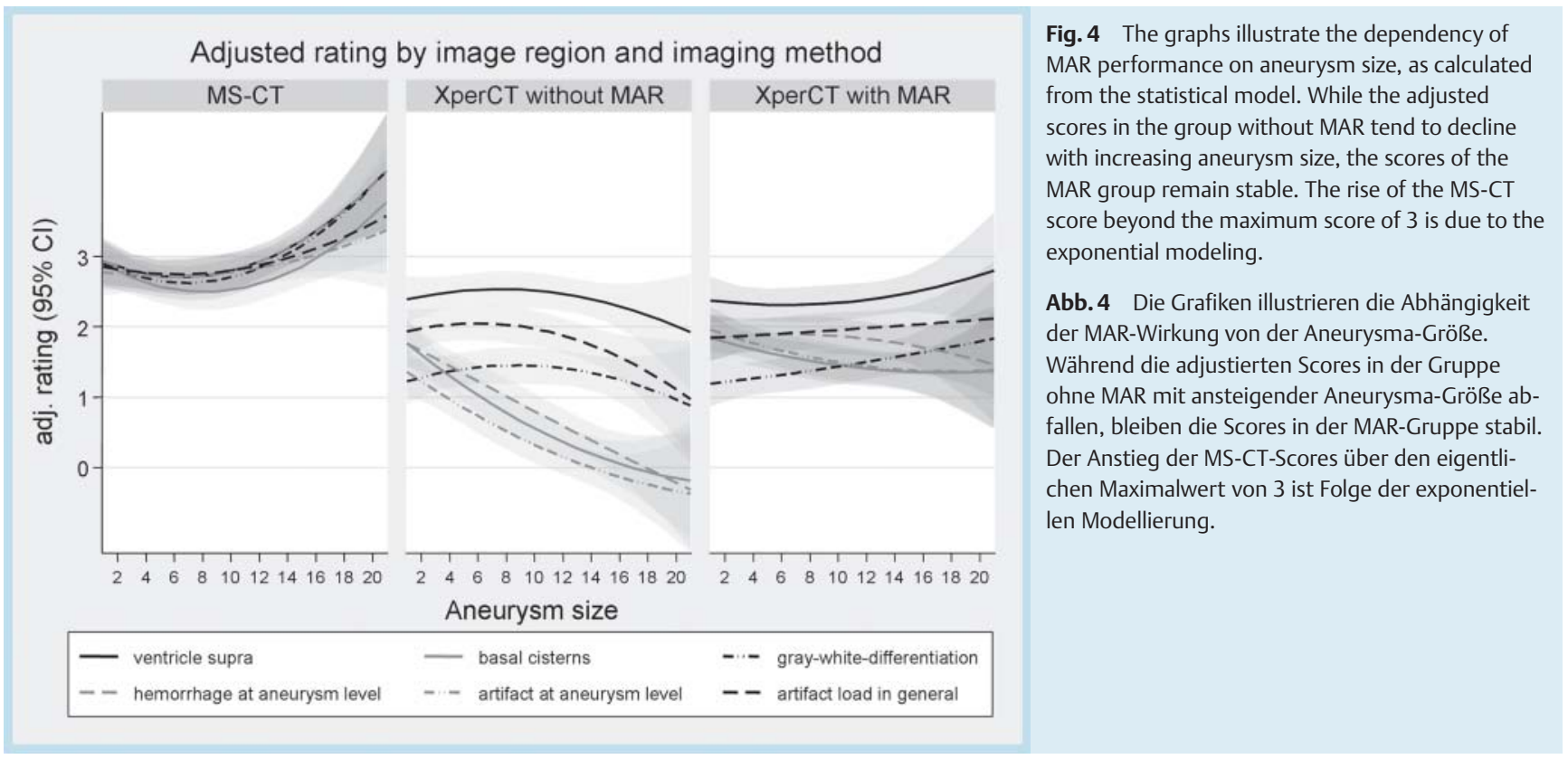

Using the model mentioned above (area as size), significant effects occur, relating aneurysm area to anatomical landmarks and imaging method $(\mathrm{p}<0.001)$. Additionally, the interaction between the parameters „aneurysm location“ and „imaging method“ also has a significant effect on the scores $(\mathrm{p}<0.001)$. The influence of the patients' sex on the scores is not significant ( $p=0.4491$ ).

The adjusted means of the scores at the median size of aneurysm are illustrated in $\bullet$ Fig. 1, and illustrative case studies are presented in $\bullet$ Fig. $2,3$.

Preinterventional MS-CT scored highest in all items. However, best scorings were not achieved with respect to the infratentorial regions in all cases. In one patient who already had two additional aneurysms, which had been clipped, the artifact load was scored as „substantial“ at the level of these aneurysms.

The scores regarding the depiction of the supratentorial CSF spaces in the FP-CT exams were not as good as in CT, but in the majority of cases achieved a sufficient diagnostic score. The infratentorial regions were not always displayed in sufficient quality.

The amount of hemorrhage remote from the aneurysm level seems to also be well assessable without MAR. The scores do not differ significantly in this case. Regarding the basal cisterns and the hemorrhage in the vicinity of the aneurysm, the MAR reconstructions achieve substantially better scores (differences at median size: $0.61,95 \%-\mathrm{CI}[0.27,0.94], \mathrm{p}<0.001$ and $0.73,95 \%-\mathrm{CI}$ $[0.39,1.06], \mathrm{p}<0.001)$. This is especially reflected in the evaluation of the artifact load on the level of the aneurysm, in which the MAR reconstructions scored significantly better (differences at median size: $0.96,95 \%-\mathrm{CI}[0.62,1.29], \mathrm{p}<0.001)$. The artifact load in general was scored equally in both FD-CT groups.

Further evaluation of possible influences on MAR effect revealed a dependency of the difference between both FP-CT groups from aneurysm size: the larger the aneurysm, the higher the difference in scores between both groups. The results are illustrated in - Fig. 4 (the apparent rise of some scores and confidence intervals above maximum level is due to the modeling).

\section{Discussion}

FP-CT is a very interesting tool for interventional neuroradiologists, since it provides them the possibility to perform conventional CT-like imaging of the brain in the angiography suite. In addition, a lot of work has been published in recent years regarding the immense possibilities in imaging stents and other discrete implants or materials in highest spatial resolution by the same technique [1,9-12]. The actual CT-like imaging of the brain parenchyma has been evaluated as well: FP-CT seems feasible for depicting the morphology of the CSF spaces, for intracranial hemorrhage or for locating larger foreign bodies like external ventricle drainage lines and their relationship to the CSF spaces. Reported drawbacks were the risk of missing small amounts of subarachnoid hemorrhage and the unreliable delineation of the infratentorial CSF spaces due to beam hardening artifacts. The discrimination of gray and white matter is principally feasible, but still not comparable to conventional CT. Therefore, it is still not considered to be reliably possible to depict discrete changes like early signs of infarction in FP-CT [2, 5, 7, 12, 24, 26].

Further possibilities have arisen by performing intravenous contrast media injection in combination with dedicated FP-CT acquisition and postprocessing programs, especially for CT angiography-like imaging of intracranial stents or clipped aneurysms and for blood volume imaging in acute ischemic stroke [9, $13-15,19$, $27,28]$. The results of the first studies on these very new methods are promising.

This study deals with plain native FP-CT, which nowadays many centers perform in the beginning and/or end of a neurointerventional procedure in order to rule out certain complications like hemorrhage or hydrocephalus. However, coil-related artifacts at the level of the treated aneurysm can get so serious that it may not be possible to reliably depict the structures in the vicinity of the aneurysm, e.g. new hemorrhage. This problem is well known from conventional CT, and has not been convincingly resolved so far in the context of a product.

Recently first work was published on a promising new reconstruction algorithm for metal artifact reduction in FP-CT [25, 29]. However, these are still prototype data. To the best of our 
knowledge, our study is the first work on a similar technique with a clinical patient collective.

First of all, our results regarding typical features of soft tissue FPCT are in line with former work: The delineation of gray-white differentiation is still not optimal, the visualization of the inner and outer CSF spaces is better above the tentorium than below, and larger hemorrhage remote from the aneurysm level is reliably detected. The agreement between the raters was very high, which we would interpret as already being familiar with FP-CT image impression.

The effect of the MAR algorithm in reducing the beam hardening artifacts on the level of the aneurysm is convincing: Scores of the relevant regions are significantly higher in the MAR group. Additionally, we observed a correlation between the performance of MAR and the aneurysm size, which equals the size of the coil package: The larger the aneurysm, the larger the difference compared to the non-MAR group.

Negative effects of the MAR algorithm on subjective FP-CT image quality were not observed. The areas primarily unaffected by implant-related artifacts did not reveal differences in image scoring. A quantitative evaluation of $\mathrm{CT}$ values or contrast-to-noise ratio was not performed, since that was not the main focus of the study. However, implant-related artifacts seem to be not the only matter in FP-CT image quality. The subjective scores regarding artifacts in general were equally high in both groups, suggesting additional sources of artifacts, where still some engineering research is necessary.

\section{Conclusion}

\section{$\nabla$}

Performing metal artifact reduction filtering in FP-CT reconstruction has the possibility to substantially improve the image quality for soft-tissue imaging following coil-embolization in a setting of acute SAH.

\section{References}

1 Benndorf G, Strother CM, Claus B et al. Angiographic CT in cerebrovascular stenting. AJNR Am J Neuroradiol 2005; 26: 1813-1818

2 Heran NS, Song JK, Namba K et al. The utility of DynaCT in neuroendovascular procedures. AJNR Am J Neuroradiol 2006; 27: 330 - 332

3 Knollmann F, Valencia R, Buhk JH et al. Characteristics and applications of a flat panel computer tomography system. Fortschr Röntgenstr 2006; 178: $862-871$

4 Kalender WA, Kyriakou Y. Flat-detector computed tomography (FDCT). Eur Radiol 2007; 17: 2767-2779

5 Dorfler A, Struffert T, Engelhorn T et al. Rotational flat-panel computed tomography in diagnostic and interventional neuroradiology. Fortschr Röntgenstr 2008; 180: 891 - 898

6 Hausegger KA, Furstner M, Hauser $M$ et al. Clinical application of flatpanel CT in the angio suite. Fortschr Röntgenstr 2011; 183: 11161122

7 Soderman $M$, Babic D, Holmin S et al. Brain imaging with a flat detector C-arm: Technique and clinical interest of XperCT. Neuroradiology 2008; 50: $863-868$

8 Fiehler J. Unruptured brain aneurysms: when to screen and when to treat? Fortschr Röntgenstr 2012; 184: 97 -104

9 Buhk JH, Lingor P, Knauth M. Angiographic CT with intravenous administration of contrast medium is a noninvasive option for follow-up after intracranial stenting. Neuroradiology 2008; 50: 349-354
10 Richter G, Pfister M, Struffert $T$ et al. Technical feasibility of 2D-3D coregistration for visualization of self-expandable microstents to facilitate coil embolization of broad-based intracranial aneurysms: an in vitro study. Neuroradiology 2009; 51: 851 - 854

11 Buhk JH, Kallenberg K, Mohr A et al. Evaluation of angiographic computed tomography in the follow-up after endovascular treatment of cerebral aneurysms-a comparative study with DSA and TOF-MRA. Eur Radiol 2009; 19: $430-436$

12 Psychogios MN, Buhk JH, Schramm P et al. Feasibility of angiographic CT in peri-interventional diagnostic imaging: a comparative study with multidetector CT. AJNR Am J Neuroradiol 2010; 31: 1226-1231

13 Struffert T, Ott S, Adamek E et al. Flat-detector computed tomography in the assessment of intracranial stents: comparison with multi detector CT and conventional angiography in a new animal model. Eur Radiol 2011; 21: 1779 - 1787

14 Struffert T, Kloska S, Engelhorn T et al. Optimized intravenous Flat Detector CT for non-invasive visualization of intracranial stents: first results. Eur Radiol 2011; 21: $411-418$

15 Psychogios MN, Wachter D, Mohr A et al. Feasibility of flat panel angiographic CT after intravenous contrast agent application in the postoperative evaluation of patients with clipped aneurysms. AJNR Am J Neuroradiol 2011; 32: 1956-1962

16 Snoeren RM, Soderman M, Kroon JN et al. High-resolution 3D X-ray imaging of intracranial nitinol stents. Neuroradiology 2012; 54: 155 162

17 Patel NV, Gounis MJ, Wakhloo AK et al. Contrast-enhanced angiographic cone-beam CT of cerebrovascular stents: experimental optimization and clinical application. AJNR Am J Neuroradiol 2011; 32: 137-144

18 Heller RS, Malek AM. Parent vessel size and curvature strongly influence risk of incomplete stent apposition in enterprise intracranial aneurysm stent coiling. AJNR Am J Neuroradiol 2011; 32: 1714-1720

19 Saake M, Struffert T, Goelitz P et al. Angiographic CT with intravenous contrast agent application for monitoring of intracranial flow diverting stents. Neuroradiology 2012; 54: $727-735$

20 Golitz P, Struffert T, Ganslandt $O$ et al. Optimized angiographic computed tomography with intravenous contrast injection: an alternative to conventional angiography in the follow-up of clipped aneurysms? J Neurosurg 2012; 117: 29-36

21 Clarencon F, Piotin M, Pistocchi S et al. Evaluation of stent visibility by flat panel detector CT in patients treated for intracranial aneurysms. Neuroradiology 2012; 54: 1121 - 1125

22 Golitz P, Struffert T, Knossalla F et al. Angiographic CT with intravenous contrast injection compared with conventional rotational angiography in the diagnostic work-up of cerebral aneurysms. AJNR Am J Neuroradiol 2012; 33: $982-987$

23 Ringelstein A, Schlamann M, Goericke SL et al. 3-year follow-up after endovascular aneurysm treatment with Silk(R) flow diverter. Fortschr Röntgenstr 2013; 185: 328 - 332

24 Doelken M, Struffert T, Richter G et al. Flat-panel detector volumetric CT for visualization of subarachnoid hemorrhage and ventricles: preliminary results compared to conventional CT. Neuroradiology 2008; 50: $517-523$

25 Psychogios MN, Scholz B, Rohkohl C et al. Impact of a new metal artefact reduction algorithm in the noninvasive follow-up of intracranial clips, coils, and stents with flat-panel angiographic CTA: initial results. Neuroradiology 2013, Epub ahead of print

26 Kamran M, Nagaraja S, Byrne JV. C-arm flat detector computed tomography: the technique and its applications in interventional neuro-radiology. Neuroradiology 2010; 52: 319-327

27 Wachter D, Psychogios M, Knauth $M$ et al. IvACT after aneurysm clipping as an alternative to digital subtraction angiography-first experiences. Cen Eur Neurosurg 2010; 71: 121 - 125

28 Blanc R, Pistocchi S, Babic D et al. Intravenous flat-detector CT angiography in acute ischemic stroke management. Neuroradiology 2012; 54: $383-391$

29 Prell D, Kyriakou Y, Struffert T et al. Metal artifact reduction for clipping and coiling in interventional C-arm CT. AJNR Am J Neuroradiol 2010; 31: $634-639$ 